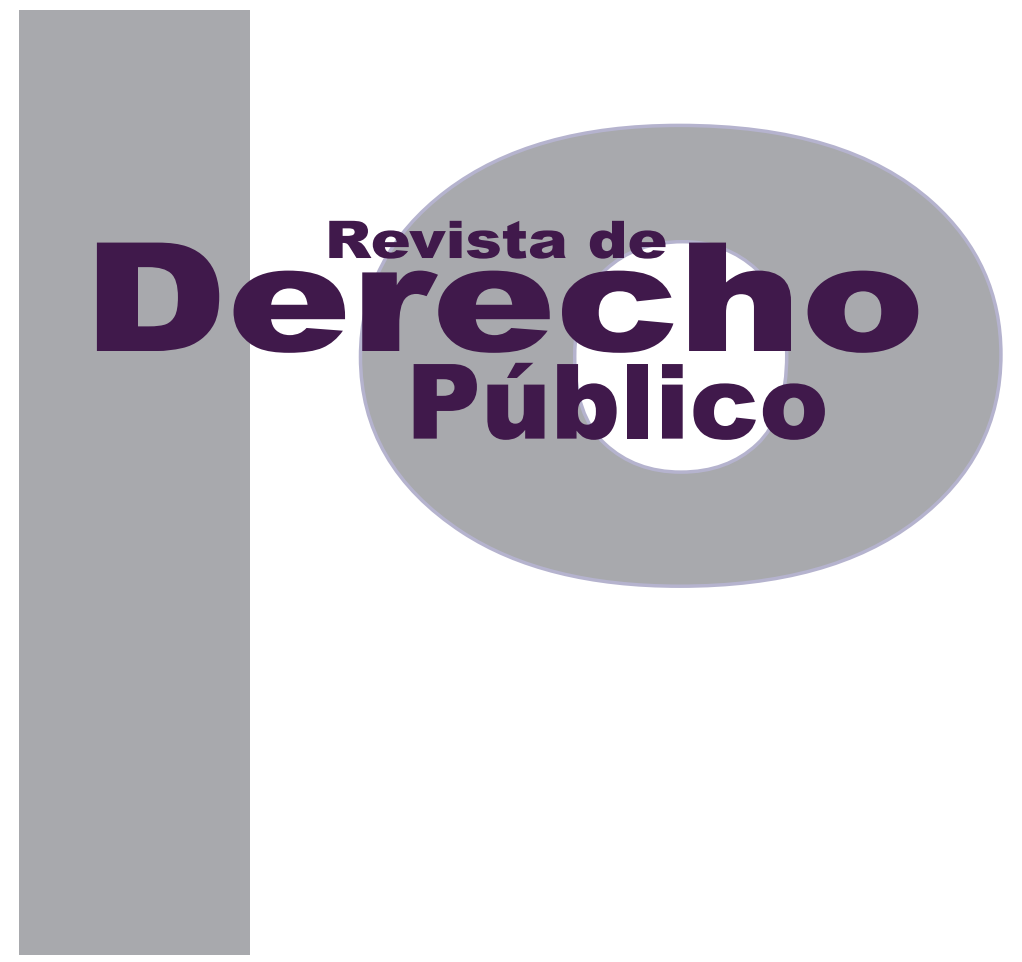

\title{
FORMACIÓN CIUDADANA EN LA UNIVERSIDAD: UNA PROPUESTA PARA LA ACCIÓN
}

\author{
Betsy Perafán Liévano
}

Universidad de los Andes

Facultad de Derecho

Revista de Derecho Público N. ${ }^{\circ} 32$

Enero - Junio de 2014. ISSN 1909-7778 


\title{
Formación ciudadana en la universidad: una propuesta para la acción ${ }^{*}$
}

\author{
Betsy Perafán Liévano**
}

\section{RESUMEN}

El presente artículo pretende, en primer lugar, comprender la(s) postura(s) teórica(s) que fundamenta(n) la educación ciudadana en Colombia. En segundo lugar, plantear una crítica a esa(s) postura(s) y, en tercer lugar, aportar una propuesta de formación ciudadana que pretende ser más coherente con los postulados democráticos, y más eficaz en la práctica.

Se plantean recomendaciones para formar en pensamiento crítico y en disposición a la acción trabajando con, desde y para las emociones con un enfoque artístico (sensible y creativo) en la enseñanza de todas las asignaturas. La

\section{ABSTRACT}

This article aims: first, to understand the theoretical position that base citizenship education in Colombian. Second, propound a criticism of that position, and third, to provide a civic education proposal that purport to be more consistent with democratic principles and effective in practicing.

Recommendations are proposed to form in critical thinking and disposition to act to work with, from and to the emotions with an artistic approach (sensible and creative) in the teaching of all subjects. The presented proposal focuses on the techniques of Theatre of the Oppressed by Augusto Boal, considering that it allows to

Cómo citar este artículo: Perafán, B. (junio, 2014). Formación ciudadana en la universidad: una propuesta para la acción. Revista de Derecho Público, 32.

Abogada de la Universidad de los Andes, licenciada en matemáticas de la Universidad Distrital, magíster en educación de la Universidad de los Andes. Estudiante del doctorado en educación de la misma universidad. Actualmente labora como docente de planta tiempo completo. Correo: bperafan@ uniandes.edu.co 
propuesta que se presenta se enfoca en las técnicas del teatro del oprimido (TO), de Augusto Boal, por considerar que permite formar ciudadanos experimentando en todo el ser la ciudadanía responsable liberal (protección de derechos individuales), republicana (pertenencia a una comunidad y tanto uso como creación de mecanismos de participación) y crítica (para lograr justicia social).

PALABRAS Clave: formación ciudadana, universidad, democracia, teatro del oprimido, emociones. form citizens experiencing the whole being the responsible Liberal citizenship (protection of individual rights), Republican (belonging to a community and as much use as creation of mechanisms for participation) and Critical (to achieve social justice).

KEY WORDS: civic education, university, democracy, theater of the oppressed, emotions. 


\section{SUMARIO}

Introducción - I. ¿QUÉ HA SIGNIFICADO FORMAR PARA LA CIUDADANÍA EN UNA DEMOCRACIA? - A. La ciudadanía liberal - B. La ciudadanía republicana - C. La ciudadanía crítica - II. LA FORMACIÓN CIUDADANA PARA LA ACCIÓN - A. La necesidad de la experiencia emocional para la formación ciudadana - B. La educación como experiencia de responsabilidad - C. El aporte oriental a la formación integral - III. UNA PROPUESTA PARA LA ACCIÓN CIUDADANA EN LA UNIVERSIDAD - IV. REFLEXIONES FINALES Y RECOMENDACIONES - Bibliografía. 
Introducción

El artículo 67 de la Constitución colombiana de 1991 consagra la formación ciudadana como una finalidad del Estado en los siguientes términos: "La educación formará al colombiano en el respeto a los derechos humanos, a la paz y a la democracia; y en la práctica del trabajo y la recreación, para el mejoramiento cultural, científico, tecnológico y para la protección del ambiente [...]".

Conforme al artículo, las instituciones educativas no deben limitar el aprendizaje a la adquisición de unos conocimientos (científicos, técnicos o culturales), sino que estos saberes deben ser puestos al servicio de la sociedad para aportar a la convivencia.

Con el fin de hacer realidad la norma constitucional, en el año 2003 el Estado comenzó a construir los parámetros para guiar a las instituciones educativas en el desarrollo de las competencias ${ }^{1}$ ciudadanas de los estudiantes (Ministerio de Educación Nacional -MEN, 2004). Se plantearon unos estándares que serían medidos a través de preguntas de selección múltiple. Por tanto, todos los colegios y universidades deberían guiarse por esos parámetros estatales en el diseño de sus objetivos y de sus metodologías de enseñanza.

Para el MEN (2010), “lograr una educación de calidad significa formar ciudadanos con valores

Para los fines del presente trabajo se tomarán como sinónimos los términos "competencia" y "formación", ya que en los documentos oficiales usan el primero como materialización del segundo. éticos, respetuosos de lo público, que ejerzan los derechos humanos, cumplan sus deberes sociales y convivan en paz". Este reto implica que cada institución educativa "permita y comprometa la participación de toda la sociedad en un contexto diverso, multiétnico y pluricultural" y desarrolle "prácticas democráticas para el aprendizaje de los principios de la participación ciudadana".

Al formular la política pública, el MEN definió las competencias ciudadanas (CC) como aquel "conjunto de conocimientos y de habilidades cognitivas, emocionales y comunicativas que, articulados entre sí, hacen posible que el ciudadano actúe de manera constructiva en la sociedad democrática" para consolidar la convivencia en un Estado Social de Derecho, lo cual incluye "promover el respeto y cuidado de la identidad, la pluralidad y las diferencias".

Así, el Programa de Competencias Ciudadanas se orienta a desarrollar "las habilidades, destrezas y conocimientos sobre ciudadanía y convivencia" en todos los estudiantes del país. Las líneas de acción del MEN en esta vía son: la movilización social, el acompañamiento a las prácticas educativas y la gestión del conocimiento para el desarrollo de competencias ciudadanas. Para evaluar el logro de los objetivos y tomar decisiones de política educativa, el MEN diseñó un sistema de monitoreo y sistematización que busca generar autorreflexión sobre su implementación a partir de información objetiva, y valorar el comportamiento de los establecimientos educativos en relación con los indicadores para la institucionalización de competencias ciudadanas. 
En este propósito, contrató a un grupo de expertos para que construyera los estándares de CC y la prueba SABER respectiva (Chaux, 2004). La concepción de ciudadanía de la que se parte está planteada a manera de tres retos: i) convivir pacífica y constructivamente con otros que frecuentemente tienen intereses que riñen con Ios nuestros; ii) construir colectivamente acuerdos y consensos sobre normas y decisiones que nos rigen a todos y que deben favorecer el bien común; y iii) construir sociedad a partir de la diferencia.

A pesar de lo anterior, de acuerdo con Ariza (2007), los estándares de estas pruebas presentan un vacío respecto de la participación colectiva y directa en la definición y conducción de los asuntos comunes, alejándose así de la concepción original de ciudadanía (en Grecia) y en pro del Estado liberal (prácticas individuales y privadas como el voto, y no intervención en la vida de otros - dejar vivir-). Así, dice la autora, es difícil que los estudiantes "se asuman algún día de forma deliberada y consciente como actores en la construcción colectiva" (p. 161) si se les ha educado en prácticas heterónomas por considerar que aún no son lo suficientemente maduros para participar como creadores.

El presente artículo pretende, en primer lugar, comprender la(s) postura(s) teórica(s) que fundamenta(n) la educación ciudadana en CoIombia. En segundo lugar, plantear una crítica a esa(s) postura(s), y, en tercer lugar, aportar una propuesta de formación ciudadana que pretende ser más coherente con los postulados democráticos, y más eficaz en la práctica.
Para lograr estos propósitos he dividido el texto en cuatro partes. En la primera, estudiaré diversas posturas de ciudadanía que han tenido marcada influencia en los Estados occidentales (incluida Colombia). En la segunda, sustentaré cómo estas miradas son incompletas para generar la acción ciudadana. En la tercera parte plantearé una postura propia, recogiendo lo que encuentro valioso en las corrientes vistas, y agregando ideas que considero ayudan a resolver los problemas identificados en esos tipos de ciudadanía para el logro real de la democracia. Y en la última parte presentaré mis reflexiones finales, acompañadas de unas sugerencias en materia de política pública educativa.

\section{I. ¿QUÉ HA SIGNIFICADO FORMAR PARA LA CIUDADANÍA EN UNA DEMOCRACIA?}

Siguiendo a Harnish (2006), encontramos al menos tres discursos occidentales en torno a la ciudadanía: el liberal, el republicano y el crítico. A continuación presentaré cada uno de ellos y plantearé cuestionamientos a sus ideas fundamentales.

\section{A. La ciudadanía liberal}

Su valor central es la autonomía o libertad individual. Aparece como una necesidad ante el despotismo de los gobernantes y jueces en las monarquías absolutistas y aboga por el gobierno de las leyes; pero unas leyes que permitan a los ciudadanos actuar conforme a su plan de vida sin intromisiones de otros o del mismo Es- 
tado. Sobre todo pretende que cada individuo pueda actuar con la certeza de que su acción es legal; que no será sancionado sin que haya una norma previa que le avise de la prohibición. Además, como lucha de burgueses, se planteó para que estos pudieran comercializar sin riesgo de perder sus propiedades. No sin razón se responsabiliza a este discurso de ser el origen del capitalismo.

En este marco, se promueve el respeto al otro pero entendido como un grado de tolerancia a su manera de pensar y comportarse, siempre y cuando no interfiera en la vida de los demás. De igual manera, se reconoce la capacidad de los individuos para pensar por sí mismos y para cuestionar sus propias ideas. Por ello, una educación que desarrolle habilidades de argumentación es coherente con esta filosofía.

Así, el discurso de la ciudadanía liberal alienta cierta individualidad que no tiene que ceñirse a la solidaridad, salvo si esta es entendida como un medio para lograr beneficios propios que no le impidan a otros individuos alcanzar los suyos.

\section{B. La ciudadanía republicana}

Sin desconocer los aportes del liberalismo, el discurso republicano está centrado en la igualdad de los individuos ante la ley. Este cambio de énfasis se da por la necesidad de garantizar la participación política activa de todos los ciudadanos en los asuntos de interés público (ej.: votar por los gobernantes y legisladores, que pueden provenir de cualquier clase social) con el fin de mantener la cohesión o unidad hacia el
Estado. El liberalismo, al propender por los intereses individuales, puede ser un riesgo para la existencia misma del Estado que requiere de su legitimidad para actuar. Un ciudadano que no logra cumplir su plan de vida por la manera como funciona la sociedad capitalista (Marx, 2007) posiblemente no querrá hacer parte del "contrato social": no obedecerá las leyes impuestas, pues le dificultan vivir en sociedad en vez de aportar para su desarrollo personal.

Así, se promueve el patriotismo: el amor y servicio incondicional a una comunidad política nacional. El respeto al otro ya no es la sola tolerancia; se ve como un compatriota, al que hay que reconocer y ayudar cuando lo necesite (ej.: ante una emergencia invernal) pero no por el hecho de ser un humano, sino porque así evitamos que el Estado se debilite. Tampoco entonces hay una solidaridad desinteresada ni un deseo de cerrar las brechas entre las clases sociales.

\section{La ciudadanía crítica}

Sin desconocer los aportes del liberalismo y del republicanismo, el discurso crítico está centrado en la fraternidad. La ciudadanía republicana busca la igualdad ante la ley, pero no necesariamente en la realidad. Así, se propende por la justicia material aunque su logro vaya contra la seguridad jurídica (es decir, esa supuesta igualdad formal que garantiza la certidumbre de las decisiones en derecho). Tampoco la ciudadanía liberal busca acortar las distancias entre ricos y pobres; incluso los críticos del capitalismo puro consideran que este sistema las aumenta ya que el Estado no interviene en la economía. 
Así, los estudios culturales (ej.: el feminismo) o críticos cuestionan las relaciones de poder, el patriarcado, la exclusión social, la manipulación de los medios de comunicación, la división entre lo público y lo privado, entre el interés general y el interés particular y entre razón y emoción. En vez de propender por el consenso, alienta la diferencia. En lugar de reforzar el individualismo, promueve el cuidado, la justicia social, la cooperación, el humanismo y la empatía. La identidad, más que personal o local, es humana. No privilegia el debate meramente racional, pues reconoce que no es el único determinante en las decisiones y acciones de los ciudadanos.

En este marco, el discurso crítico quiere dar voz a los que tradicionalmente no la tienen para volverlos visibles y así comenzar el proceso de transformación social mediante la acción política. Sin embargo, se ha corrido el riesgo de caer en la victimización (para lograr la compasión) y, por ende, más en una comodidad con ese estado que en un deseo de salir de él. Por otro lado, se cuestiona si la exclusión ya no la hace el Estado ni la sociedad sino los mismos marginados (ej.: los homosexuales) al agruparse en comunidades sectarias para la defensa de sus derechos.

\section{LA FORMACIÓN CIUDADANA PARA LA ACCIÓN}

Los discursos de ciudadanía presentados se fundan en principios que constituyen pilares para la democracia: la libertad, la igualdad y la fraternidad. Pero cada uno le da énfasis a solo uno de ellos, lo que al parecer va en detrimento de los otros. ¿Será posible construir un discurso de ciudadanía que logre armonizar los tres?

La propuesta de los estudios culturales o críticos plantea esa armonía al considerar que la autonomía implica que cada quien desarrolle su pensamiento crítico para participar en los asuntos públicos, con el fin de lograr la justicia material de los grupos tradicionalmente discriminados o marginados. Sin embargo, ¿cómo lograrlo en la práctica?, ¿basta con confiar en la capacidad del ser humano de sentir empatía con los desfavorecidos del sistema luego de un ejercicio racional?

Sustentaré cómo la práctica del debate no es suficiente para tener una experiencia estética, y que esta última se requiere para disponer al ser humano a la acción.

\section{A. La necesidad de la experiencia emo- cional para la formación ciudadana}

Un aspecto que me parece problemático de la formación ciudadana, tal como es concebida hoy día, es su énfasis en la racionalidad. Unas pruebas estandarizadas dan cuenta de la capacidad argumentativa de quien las presenta, pero su éxito en ellas no significa que sean ciudadanos responsables en los asuntos públicos. Por ejemplo, el profesor puede explicar que la discriminación sin justas razones de diferenciación es inconstitucional, y el estudiante puede ser capaz de resolver acertadamente casos hipotéticos de trato desigual, sin embargo, si una compañera de su clase es víctima de acoso 
sexual es probable que, primero, no sea consciente de la discriminación y, segundo, que aunque la note, considere que no es asunto suyo. Tal parece que hace falta promover la capacidad reflexiva y de escucha, sentimientos y emociones relativos a la empatía, y un fuerte sentido de la responsabilidad.

Pero la experiencia emocional no suele considerarse apropiada en el nivel universitario, al parecer se subvaloran dimensiones del pensamiento $y$ del ser distintas a las racionales.

Rorty (1996) plantea que ya no es útil el mito de la modernidad acerca de la verdad alcanzada por los científicos que llegan a ella de manera lógica, metódica y objetiva. La Ilustración parecía superar la idea de un tercero (el sacerdote) que nos decía en qué debíamos creer. Sin embargo, siguió la búsqueda de una verdad objetiva, pero esta vez a través de la razón: es a ella a quien debemos creerle; y si no todos tenemos las mismas capacidades u oportunidades de razonar, pues debemos creerle a quien sí las tiene.

Como pragmático, Rorty considera que la verdad es circunstancial, aunque no completamente relativa: la verdad se hace, no se descubre. El mundo está ahí afuera, pero las descripciones del mundo no. La enseñanza universitaria no parte de esta premisa, asume más bien el proceso educativo como la transmisión de unos conocimientos (verdades objetivas). Así, el estudiante tiene un rol pasivo similar al de los fieles de la Iglesia. ¿Entonces por qué esperar que sea un ciudadano constructor de su sociedad?
En términos de Rorty, un profesor debería reconocer la contingencia y fragilidad de sus creencias y deseos más fundamentales; por lo mismo, no querer imponer su "verdad" (su interpretación) a los estudiantes sino ampliar las relaciones y las perspectivas que aquellas nos pueden dar, y la mejor manera de hacerlo es trasladando la atención a las áreas que incitan la imaginación de la juventud: el arte y la política utópica. Por ejemplo, según Rorty, al leer obras literarias o ver obras cinematográficas se profundiza nuestra comprensión de las personas, al describir experiencias humanas concretas se podría generar la empatía necesaria para que se geste la solidaridad, sin una imaginación literaria es imposible conmoverse ante el mal, la educación sentimental y literaria busca formar individuos que sean capaces de indignarse ante el horror.

La razón literaria, dice este autor, en la medida en que es una razón estética, es una razón sensible al sufrimiento del otro; es una razón compasiva. Por ello está en contra de la teoría y más a favor de la narrativa. La razón humana es incierta porque vivimos en un mundo interpretado (donde todo es provisional).

La idea de la que parte Rorty es que no hay nada más repugnante para el ser humano que el sufrimiento y la crueldad, por ello debe tratar de minimizarlos. Somos capaces de darnos cuenta de que las diferencias -étnicas, religiosas, sexuales- carecen de importancia cuando se las compara con las similitudes referentes al sufrimiento y la humillación, pero para ello se requiere concebir a cada ser humano como "uno 
de nosotros". La indiferencia es una forma de crueldad.

Una sociedad liberal, la que defiende Rorty, se complace en llamar "verdadero" (o "correcto" o "justo") a lo que sea resultado de una comunicación no distorsionada (libre y abierta). En sus términos, seremos realmente libres si somos solidarios. Algo así como que "la solidaridad ensancha la libertad", pues permite el reconocimiento.

Para el proceso de formación ciudadana, probablemente convendría una pedagogía para la libertad solidaria; ya no estamos hablando solo de pensamiento crítico - entendido como la capacidad de reflexionar racionalmente sobre qué creer y qué hacer-(Norris, 1989) sino de un desarrollo integral del ser que incluya su sensibilidad.

En el mismo sentido, Nussbaum (2005) plantea que cuando leemos sobre la vida de otros (escrita con respeto), comprendemos que todos los seres humanos estamos conectados. Aboga así por la idea de ser ciudadanos del mundo: promover la identidad humana, más que la del grupo local. El arte de la narrativa tiene el poder de hacernos entrar en la vida de otros. La buena literatura debería expandir nuestro sentido de lo que es posible pensar y sentir; desarrollar aún más nuestras posibilidades humanas. De esta manera ayuda a cultivar un entendimiento empático de las personas que son diferentes y a desarrollar la compasión. De acuerdo con la autora, ni los individuos ni los grupos son perfectos en el conocimiento de sí mismos y una persona ajena podría ver en ellos lo que no logran observar por estar "dentro".
Aún más, para Nussbaum se trata de cultivar el ser, más que el saber. A través de la narrativa se conoce uno mismo. Al dejarse ser se logra la libertad: la literatura nos debería perturbar y desafiar los valores convencionales. Las obras narrativas nos piden que nos enfrentemos $a-y$ que por un momento seamos- aquellos a quienes habitualmente no nos gustaría conocer. Claro, la lectura empática debe estar acompañada de reflexión y de formular preguntas críticas sobre la experiencia emocional para que tenga el efecto deseado.

Las artes narrativas no nos muestran el pasado sino el futuro (no lo que pasó sino lo que podría suceder). En su sentir, el arte literario desarrolla capacidades de percepción y juicio que son medulares para la democracia, promueve una intensa conciencia de las necesidades y desventajas del prójimo, y en este sentido da sustancia al deseo abstracto de justicia.

Afirma Nussbaum que cuando seamos capaces de imaginar por qué alguien hace algo que produce indignación, seremos menos propensos a creer simplemente que esa persona es malvada. Las artes narrativas nos permiten darle al otro la complejidad psicológica e histórica (y entender su sistema de creencias) que en cambio sí solemos atribuirnos a nosotros mismos cuando se trata de justificar nuestras acciones.

En esta vía, Schiller (1990) planteó una crítica a la pretensión de separar (e incluso poner en contradicción) la facultad racional de la sensible en los seres humanos para su formación como ciudadanos. Aunque consideró que la razón ilus- 
trada de Kant (2005) es ideal teóricamente, arguyó que falla en la práctica porque no parte de la experiencia emocional en la búsqueda humana de la libertad. Por ello propuso una educación estética, y el arte - por ejemplo el teatroes el principal medio para lograrla.

La experiencia emocional permite que quien la vive se incomode, y se espera que con ello sienta la obligación moral de actuar. Según este autor, tal esperanza está dada por la sensación de libertad.

\section{B. La educación como experiencia de responsabilidad}

Para Cullén (2004), la educación debería pertenecer al campo de la filosofía práctica por cuanto instituye identidad, tanto individual como social, al enseñar que "la experiencia de lo otro es conciencia de sí mismo" y que "actuar desde sí mismo es siempre actuar con otro" (p. 46). Por lo mismo, una institución educativa se realiza cuando pretende "en lugar de la ilusión de una armonía social inmediata y la alienación de una sociedad competitiva salvaje, un ideal de sociedad solidaria, donde el poder, la riqueza y la información sean efectivamente de todos y de cada uno, y no de algunos a costa de otros" (p. 50).

Así, la educación exige el reconocimiento de la subjetividad "lo real del sujeto" (p. 51) para la construcción de un mundo social solidario. La ética, señala, no puede seguir siendo entendida como "mera normativa” (p. 75), vacía políticamente. La responsabilidad educativa está en dejar que los niños y jóvenes tomen la palabra, que sean reconocidos.

Por ejemplo, un principio básico de nuestro Estado Social de Derecho (heredado del Estado liberal) es la dignidad humana. Seguramente al estudiante se le dice esto, y se espera que lo repita en un examen, pero al decírselo puede que no se le esté reconociendo; no se le esté "cuidando en su singularidad" (p. 117), mejor dicho, no se le esté tratando con dignidad. Así, el mensaje que se le transmite es diferente a la experiencia que vive. De igual manera, el joven será capaz de repetir un discurso pero no de llevarlo a la práctica.

Siguiendo a Cullén, la educación debería ser una práctica que nos haga sentir responsables frente al otro, al reconocerlo, y nos guíe en la búsqueda (individual y colectiva) de alternativas posibles. De esta forma, la educación conjuga historias singulares y espacio público que la hacen "un telar de la esperanza” (p. 201).

En síntesis, una política pública educativa en formación ciudadana debería tener como objetivo y como pedagogía disponer a la acción responsable trabajando con, desde y para las emociones -junto con el debate racional- en la toma de decisiones públicas. Para ello es útil darle un enfoque artístico (sensible y creativo) al proceso de aprendizaje. Pero nuestra mirada occidental del concepto de ciudadano parece limitar esta comprensión. 


\section{El aporte oriental a la formación integral}

La filosofía oriental presenta algunos planteamientos que contribuyen a la formación para la acción y que complementan las ideas de los autores occidentales mencionados. Esas ideas son:

a). Solo importa el presente. El taoísmo (Watts, 1991) invita a concentrarse en el aquí y ahora, $y$ a enfatizar lo espontáneo (lo que aparece). Para lograrlo, como dice la filosofía zen (Ueda, 2004), la atención -o contemplación- es fundamental: el despertar o iluminación sobreviene a una espera atenta. Esto ocurre porque la observación nos conduce a implicarnos profundamente en la felicidad de los demás. Para el budismo (Ricard, 2009), esta es la base de la auténtica compasión. En palabras del Dalai Lama: "esta compasión no depende de la actitud de la persona que nos la inspira [...] El prójimo, aun siendo el enemigo, es como yo, un ser humano que evita el sufrimiento y aspira naturalmente a la felicidad" (Ricard, 2009, p. 96). Desde esta perspectiva, un criminal es un enfermo (así que el propósito es curarlo, no condenarlo ni castigarlo): está envenenado por la arrogancia, la avidez, los celos, etc. No luchamos contra una persona, sino contra una emoción o un comportamiento.

b). La necesidad humana del conocimiento de sí mismo y del crecimiento espiritual. El Dalai Lama expresa que es muy importante verificar siempre la motivación profunda que inspira nuestros actos y abandonar las actividades que no pretendan beneficiar a los demás o, peor aún, que se propongan perjudicarlos (hacerles daño). Llevar a cabo esto exige ser capaz de demostrar que uno ha experimentado una profunda transformación de sí mismo. Es difícil imponer un cambio a los demás sin haber cambiado el estado de ánimo propio, para empezar. Para el budismo, solo por medio de argumentos sólidos, defendidos con bondad, y no por medio de amenazas, podemos cambiar la actitud de otra persona. Así, podemos formar nuestro espíritu para actuar de manera constructiva, para sustituir la obsesión por la aceptación, la inquietud por la calma y el odio por la compasión. Según esta doctrina filosófica, la atención, la compasión e incluso la felicidad pueden cultivarse. El ámbito de investigación no se centra en los objetos exteriores sino en los acontecimientos mentales, en los mecanismos de la felicidad y el sufrimiento. La transformación de uno mismo permite transformar el mundo.

c). La vivencia de las emociones. Hay una naturaleza pragmática y experimental en el budismo: su objetivo es eliminar el sufrimiento y dedicarse al conocimiento del espíritu. El budismo no se basa en dogmas. El sentimiento que más se busca experimentar es la compasión, pues se alía con la noción de interdependencia, término central de su filosofía. Nuestra felicidad pasa necesariamente por la felicidad de otros seres.

d). La responsabilidad en el cambio. Aunque en la filosofía oriental se destacan las ideas del "dejar fluir" y de la aceptación, se insiste en la necesidad humana de intervenir en su realidad para transformarla, en aras de evitar el sufrimiento. Estos planteamientos no son contra- 
dictorios, pues según el taoísmo todo cambio empieza aceptando lo que se es y, aún más, el cambio se produce cuando uno se convierte en lo que es, no cuando trata de convertirse en lo que no es. De esta manera, el taoísmo propende por eliminar introyecciones seudomoralistas, tipo "se debe...". Este tipo de expresiones crean autolímites, por tanto obstaculizan el desarrollo de la autonomía.

\section{UNA PROPUESTA PARA LA ACCIÓN CIUDADANA EN LA UNIVERSIDAD}

Las universidades suelen consagrar entre sus objetivos la formación ética y ciudadana de los estudiantes, de acuerdo con el mandato constitucional. Sin embargo, en una encuesta de percepción hecha en la Universidad de los Andes (Mejía, A. y otros, 2012, sin publicar) se encontró que para los estudiantes de esta institución dichos objetivos son los que menos se logran y sobre los que menos se hace.

En esta universidad, el curso Constitución y Democracia es obligatorio para los estudiantes de todas las carreras, salvo Derecho. En promedio hay noventa alumnos por salón. Uno de los objetivos de la materia es la formación ética, y en mi curso específicamente pretendo lograr que los estudiantes orienten su acción desde una perspectiva social y de respeto por el otro.

Para conseguir el propósito mencionado, en el segundo semestre de 2012 opté por usar algunas técnicas del teatro del oprimido (Boal, 2009) porque buscan activar a los espectadores, es decir, que pasen de ser meros consumidores a participar creativamente en la construcción de la realidad que quieren.

Al igual que Schiller, Boal (2001) vio en el arte -más que en la ciencia- una forma pedagógica facilitadora de los procesos de pensamiento que acompañan a la razón. Especialmente, encontró mayor posibilidad en el teatro porque en este interviene el individuo en todo su ser, junto con otros: se es actor.

Augusto Boal creó su propuesta de teatro del oprimido (TO) basándose en Paulo Freire y en Bertolt Brecht, pero aportó a la formación ciudadana con la experiencia emocional-racional del teatro para la transformación social.

De esta manera, el arte nos sirve como espejo: nos permite ver quiénes somos, quiénes queremos ser y en qué sociedad nos gustaría vivir. Dice Boal (2001, pp. 14 y 24):

El teatro del oprimido crea espacios de libertad donde la gente puede dar rienda suelta a sus recuerdos, emociones, imaginación, pensar en el pasado, en el presente, e inventar su futuro en lugar de sentarse a esperarlo de brazos cruzados... Creo que el teatro debe traer felicidad, debe ayudarnos a conocer mejor nuestro tiempo y a nosotros mismos. Nuestro deseo es conocer el mundo en que vivimos para poder transformarlo de la mejor manera. El teatro es una forma de conocimiento y debe ser también un medio de transformar la sociedad.

A continuación describiré brevemente las cinco técnicas aplicadas en el curso (en cinco sesiones diferentes): 
Teatro imagen: los estudiantes representaron "fotos" sobre cómo se vería el centro de Bogotá luego de la renovación urbana si se decidiera incluir todos los estratos sociales en un mismo espacio (de vivienda, cultura, recreación y comercio).

Teatro para sordos: hicieron dramatizaciones "mudas" sobre casos de posibles vulneraciones al derecho a la salud y sobre cómo resolvería un juez de tutela cada situación.

Teatro periódico: puesta en escena de noticias sobre multiculturalismo, con una postura crítica. Es decir, no se trataba de dramatizar los hechos sino de transmitir un mensaje (de aceptación o rechazo).

Teatro invisible: sin que los estudiantes lo supieran, se presentó en clase una situación de acoso sexual (preparada por un grupo de actores profesionales). Se esperaba una participación activa en defensa de la víctima.

Teatro foro: dos actrices profesionales dramatizaron un hecho real (una joven le cuenta a una amiga que está siendo acosada por un profesor y le pide consejo; la amiga le sugiere dejar así ante las pocas posibilidades de ser protegida). La escena se repite, pero algún espectador pide que paren y pasa a remplazar a algún personaje (o incluir uno nuevo) para hacer lo que él cree correcto.

Al finalizar las clases, los estudiantes enviaron sus reflexiones personales sobre las experiencias que vivieron con el TO. En síntesis, esta metodología de clase logró: a). La generación de consciencia sobre las emociones. Con el TO los participantes experimentaron diversas emociones y reflexionaron sobre ellas. Por ejemplo, en el teatro invisible vivieron una situación "real" que les generó rabia, tristeza e indignación. Sin embargo, a pesar de estas emociones no realizaron ninguna acción de apoyo a la persona que estaba siendo víctima, optaron por la indiferencia. Esta decisión fue producto de otro sentimiento: el miedo, aunque algunos mencionaron que simplemente "les dio pereza" expresarse o incluso asumir una posición. Sin embargo, valoraron el hecho de poder darse cuenta de los sentimientos que producen en ellos este tipo de situaciones; lo que no había sucedido cuando tuvieron la clase magistral ni la lectura sobre discriminación.

Por otro lado, con el teatro imagen y también con el teatro para sordos notaron la cantidad de ideas y sentimientos que se logran transmitir a través de las expresiones faciales y corporales, y cómo el no hablar para comunicarse requiere mayor atención del auditorio. Lo llamaron algunos: darse cuenta de "el poder de la imagen".

b). La influencia de las emociones en la toma de decisiones para la acción o para la inacción. (El despertar de sentimientos). Los mismos estudiantes se cuestionaron lo siguiente al aplicar la técnica del teatro invisible: ¿por qué no actué a pesar de reconocer (y sentir) que la situación era injusta? Una de las razones que dieron para ello fue la fe ciega en la autoridad. Otra, que la tradición (o "lo que es normal") no se cuestiona. En síntesis, se sintieron impotentes por la fuerza de la costumbre y de las estructuras de privile- 
gio. Sin embargo, en su proceso autorreflexivo encontraron que las técnicas del TO los desestabilizaron, ya que pasaron de ser observadores a ser actores. Esto les generó cierta incomodidad, luego de vivir la confusión o el desconcierto. En últimas, tuvieron un sentimiento de "vergüenza" (como ellos mismos cuentan), que logró moverlos de la conciencia de la emoción a la acción. El TO los invitó a sentir para parar a pensar (o analizar), sentir más y después actuar.

c). Ser capaz de poner a prueba las propias opiniones. Con el TO los participantes reaccionaron ante un evento y tuvieron la oportunidad de reflexionar y evaluar sus propias creencias (sobre todo aquellas que los llevan a actuar o a no actuar). Por ejemplo, en el teatro foro no es suficiente con que alguien del auditorio juzgue lo que hace un personaje de la historia (la amiga que sugiere no denunciar al acosador), sino que debe pasar al frente a reemplazarlo (para sugerirle denunciar). Así, observa las consecuencias de poner en práctica su idea (sentir el miedo de la amiga ante la posibilidad de ser expulsada de la universidad) y llega a replantearla (la necesidad de buscar apoyo en otros compañeros e instancias).

d). Conocer, entender mejor, abrir la mente y dejarse afectar por otras culturas y otros puntos de vista. Junto a la capacidad de cuestionar las propias creencias, se amplía la posibilidad de compartir o al menos reconocer el valor de otras perspectivas. Además, el TO contribuye a sentir lo mismo que los otros, al ponerse en su lugar (actuar como el otro). Por ejemplo, los estudiantes manifestaron que con el teatro imagen, el teatro para sordos y el teatro periódico lograron sentir la discriminación que sufren otros. Al sentirse implicado en la situación por tomar el rol de otra persona consigue "ponerse en sus zapatos". La mirada occidental, como la que plantea Nussbaum (2005) o Rorty (1991), propone recurrir a la literatura para generar empatía, pero lo que propongo en este trabajo es tomar en mayor consideración al teatro del oprimido porque se "toca” más el actor que el lector.

En palabras de los estudiantes, las técnicas del TO “dejan pensando por el resto del día qué pasaría si fueran ellos mismos los protagonistas de esos sucesos". Y aún más, los Ilevaron a comprender la complejidad de los problemas sociales de mejor manera que un libro. Por ejemplo, lograron "culpar no al hombre sino a sus circunstancias" cuando se pusieron en su lugar.

e). La aceptación de la responsabilidad en la solución de los problemas éticos. El proceso en espiral de actuar para sentir/sentir para actuar, los llevó a darse cuenta de que forman parte de un todo: sus actos $u$ omisiones tienen efectos en otros, y esto repercute en ellos mismos. Así, comprendieron que "no pueden quedarse esperando que alguien actúe por uno" (sic); esa espera la notaron en el teatro invisible cuando aguardaban que fuera otro compañero quien salvara la situación, ya que eran muchos estudiantes. Alguno de ellos dijo en su reflexión: "sobre todo pasa (la indiferencia) si hay más de una persona cerca a la situación". Al sentir que pertenecemos a esa situación (o que nos apropiamos de ella), se contribuye a combatir la apatía. 
En el teatro foro los participantes pudieron observarse cambiando el rumbo del conflicto. Así superaron su miedo y vencieron la fuerza de la autoridad y de la costumbre. Aunque no fueron eventos reales, los estudiantes manifestaron que el To les generó la necesidad de aplicar el conocimiento en la vida diaria, de mejor manera que con una clase magistral y otros métodos activos de aprendizaje, y también les forjó “la necesidad de estar atentos ante la presencia de eventos inmorales".

f). La fuerza del grupo para actuar y para que la acción sea efectiva. Finalmente, acerca de los efectos del TO en la formación para la acción moral, se tiene que logra promover la solidaridad para actuar. Al ser técnicas grupales consiguen integrar a los estudiantes con un fin ético: aportar a la solución de un problema social. El poder del grupo les da más confianza, capacidad de decisión y valentía. Por ejemplo, en el teatro foro se vio cómo la mejor respuesta al problema planteado era aquel que requería la participación y el apoyo de todos los estudiantes. Con la actividad notaron la interdependencia: la realización humana se logra en la unidad; aunque parezca paradójico, no es posible la individualidad -la identidad personal- sin la participación de los otros.

g). Darse cuenta de que hay otras formas de aprender. Los estudiantes, en sus reflexiones, también destacaron el TO como metodología de aprendizaje. Mencionaron que los temas trabajados "se recuerdan más porque se vivencian (impactan)”. También que es más eficaz, es decir, logra los objetivos propuestos en el cur- so, especialmente el referido a la acción moral (orientar su acción desde una perspectiva social y de respeto por el otro). Como valor agregado anotaron que "es más divertido", entre otras razones porque les permite recurrir a la creatividad y a la imaginación; además, mejora la atención (sobre todo en el teatro para sordos). Otra ventaja es que les permite valorar el trabajo del grupo como necesario para el aprendizaje.

En este método de enseñanza el protagonismo es de los estudiantes (en clase y en la vida cotidiana). Se logra un aprendizaje significativo: alcanzan un mejor entendimiento de los conceptos y se ponen a prueba los conocimientos sobre la Constitución y la democracia desde una dimensión ética. En palabras de un estudiante: “la creatividad en forma de teatro mejora la comprensión de los temas éticos, lo que genera concientización y acción ante estos problemas".

Como se mencionó, las escenas de teatro foro comienzan mostrando que hay alguien que no puede hacer o lograr lo que desea porque el contexto social se lo impide. Los espectadores no solo tienen la oportunidad de parar la obra y criticar esta situación sino que suben al escenario a darle otro rumbo a la historia.

De lo dicho y de las reflexiones de los estudiantes encontramos que las técnicas del TO constituyen un método de formación ciudadana por las siguientes razones:

a). Enseñan que la indiferencia es inmoral. Desde una postura oriental, la humanidad forma una Unidad, y a la vez la Unidad está presen- 
te en cada ser humano. Por un lado, al decidir no actuar ante un evento que consideramos (o sentimos) injusto negamos la responsabilidad que tenemos hacia nosotros mismos. Por otro lado, esa inacción nos impide crecer espiritualmente porque rechazamos la oportunidad de aprendizaje que nos da la incomodidad o el enfrentarnos a una crisis. Mientras que la escuela occidental aboga por el individuo, su identidad personal y el respeto a la diferencia, en Oriente se desdibuja esa particularidad para ver el Todo; lo que nos hace comunes. Por ello es tan importante la compasión: al lograr este sentimiento se está reconociendo y aceptando esa conexión o interdependencia. Esta es una de las emociones que más busca generar el teatro del oprimido al invitar a los espectadores a asumir otros personajes, sus conflictos y sus vidas.

b). Llevan a sentir el dilema moral para actuar realmente y no quedarse solo en el juicio. Mientras que en Occidente predomina el razonamiento sobre la emoción ( $y$, de hecho, suelen plantearse como separados), en Oriente se da mayor importancia a los sentimientos por su énfasis en la experimentación y por su objetivo de evitar el sufrimiento (propio y de otros). Las metodologías occidentales de formación ética centradas en la solución de dilemas morales a partir de la argumentación tienen como problema que no logran implicar a los estudiantes: podrían razonar de una manera que podemos considerar moral, pero ello no garantiza que sus acciones lo sean, incluso estando frente a un evento similar en la vida real. En el TO, como los participantes llegan a vivir la situación, y actúan (experimentan sus argumentos y respuestas), tienen mayor probabilidad de actuar moralmente en su vida real porque ya tuvieron la oportunidad de hacerlo. El aprendizaje lo da la experiencia. Aunque esta idea también la han sostenido autores occidentales como John Dewey (2007), considero que la perspectiva oriental logra ser más completa al darle igual relevancia a los sentimientos (junto con la razón).

c). Acepta que los humanos somos imperfectos. Siguiendo la idea anterior, la filosofía oriental plantea que nuestra naturaleza más elemental no es de pensamientos (saber) sino de experiencias (ser), y estas son las que nos permiten evolucionar. Para crecer espiritualmente, el ser humano debe no solo reconocer sino también aceptar su imperfección. Esa aceptación le da la confianza necesaria para aprender; rechazar o negar su condición le impide avanzar y también le dificulta valorar a los otros. En el TO los participantes tienen la oportunidad de equivocarse y de aprender de esos errores para luego corregirlos. Igualmente, su capacidad de aceptación les permite ayudar a los otros en su proceso evolutivo. Cuando actúo (sea en un escenario teatral o de la vida "real"), experimento (soy), y son esas experiencias las que me construyen.

Así me re-conozco: con la ayuda de otros identifico mis emociones, los patrones que sigo, mis ideologías y prejuicios (¿cuándo aparecen, y por qué o asociados a qué?) y aprendo a escuchar mis necesidades.

d). Cuando sé quién soy puedo decidir quién quiero ser (qué más quiero experimentar, y qué quiero dejar de experimentar). La filosofía orien- 
tal contempla que la vida es movimiento: yo no soy el mismo del pasado, pero tampoco el del presente. Sin embargo, a cada ser humano lo forma su pasado, su presente y su futuro al mismo tiempo, pues lo que ya experimentó lo constituye hoy, pero hoy es así porque le sirve para lo que quiere ser mañana. En el TO el pasado importa para plantear la situación, pero todo ocurre en el presente con el fin de cambiar el futuro.

Si la responsabilidad es la habilidad para responder, necesariamente es una experiencia. Si alguien decide quién quiere ser, necesita moverse para lograrlo. Desde la postura oriental, lo que hace que se mueva es la incomodidad, y esta se da cuando al individuo ya no le gusta lo que experimenta (o siente). Con las técnicas del TO los estudiantes sintieron esa incomodidad o malestar por lo que estaban viviendo, y esto los motivó a tomar decisiones distintas (o incluso a tomarlas, si antes ni siquiera lo hacían).

Pero hay quienes se quedan viviendo en esa incomodidad, incluso si la conciencia (del cuerpo o del alma) les avisa que quiere cambiar; así sepan escuchar sus necesidades, no responden a ellas... ¿Cómo moverlos? En muchos casos lograr tener una habilidad requiere mucha práctica. La formación implica proceso, y esta es la mejor parte. En el teatro participativo para aprender a transformar los conflictos se juega todo el tiempo. Los juegos están diseñados para liberar el cuerpo (y así, liberar la mente, y así, liberar el alma). Se activa al ser humano jugando mucho. Uno de esos juegos son las improvisaciones, que sobre todo se hacen para afinar la creatividad. Tanta práctica va moviendo, va llevando al ser a responder libremente, o en otras palabras, a tomar las decisiones que más le convengan (que le permitirán experimentar lo que quiere).

El siguiente cuadro sintetiza lo presentado hasta ahora:

\begin{tabular}{|c|c|c|}
\hline \multicolumn{2}{|c|}{$\begin{array}{l}\text { REGLAS PARA LA ACCIÓN } \\
\text { ÉTICO-CIUDADANA }\end{array}$} & TEATRO DEL OPRIMIDO \\
\hline 1. El presente & $\begin{array}{l}\text { Observamos para } \\
\text { implicarnos. }\end{array}$ & $\begin{array}{l}\text { Ponemos a prueba las } \\
\text { propias opiniones y } \\
\text { estamos atentos ante } \\
\text { eventos inmorales o in- } \\
\text { justos. }\end{array}$ \\
\hline $\begin{array}{l}\text { 2. El autoco- } \\
\text { nocimiento }\end{array}$ & $\begin{array}{l}\text { Indagamos los } \\
\text { motivos de nues- } \\
\text { tros actos. }\end{array}$ & $\begin{array}{l}\text { Logramos la concien- } \\
\text { cia de nuestras propias } \\
\text { emociones. }\end{array}$ \\
\hline $\begin{array}{l}\text { 3. La experi- } \\
\text { mentación }\end{array}$ & $\begin{array}{l}\text { Comprobamos } \\
\text { que dependemos } \\
\text { unos de otros } \\
\text { para eliminar el } \\
\text { sufrimiento. }\end{array}$ & $\begin{array}{l}\text { El despertar de senti- } \\
\text { mientos nos ayuda a } \\
\text { abrir la mente y a reco- } \\
\text { nocer la fuerza del gru- } \\
\text { po para actuar efectiva- } \\
\text { mente. }\end{array}$ \\
\hline 4. El cambio & $\begin{array}{l}\text { Actuamos de ma- } \\
\text { nera constructiva. } \\
\text { Comprendemos } \\
\text { que al transfor- } \\
\text { marnos nosotros } \\
\text { mismos transfor- } \\
\text { mamos el mundo. }\end{array}$ & $\begin{array}{l}\text { Aprendemos en y para } \\
\text { la acción. Aceptamos la } \\
\text { responsabilidad en la } \\
\text { solución a los problemas } \\
\text { ético-políticos. }\end{array}$ \\
\hline
\end{tabular}

\section{REFLEXIONES FINALES Y RECOMENDACIONES}

En el teatro del oprimido es la misma comunidad afectada la que transforma sus espacios, de forma autónoma y mirando las necesidades desde otras perspectivas. Estas técnicas ayudan a que nos narremos de otra manera porque se reescribe la historia, pero no solo revisando lo que ya ocurrió, sino también recreando el presente para mejorar el futuro. Por ello es más importante ESTAR, vivir el presente, que quedarse en 
el pasado. El TO genera emociones que promueven una conciencia crítica, creativa y de toma de decisiones para la acción moral. Se trata de actuar (de actuación) para motivarse a actuar (de acción).

Las técnicas del TO sirven como método de diagnóstico y a la vez como método de tratamiento. Por un lado, los participantes se conocen en la acción (sus creencias, prejuicios y sentimientos). Y por otro, se transforman. Esto se da porque el teatro, o mejor, sus técnicas de expresión dan la capacidad a los seres humanos de observarse a sí mismos en acción. En el contexto de la ficción teatral, el individuo descubre que su modelo para actuar es el origen de muchos problemas. El teatro del oprimido consigue que el espect-actor genere espontáneamente una respuesta distinta a la situación problemática que ha planteado para la dramatización, y que dé esta nueva respuesta en la vida real.

El TO es arte y política al tiempo: es creatividad y argumentación -ambas se "afinan" con tanta improvisación-, ya que los participantes se reconocen como ciudadanos que toman decisiones frente a los conflictos sociales. Este reconocimiento se da por las emociones que genera identificarse y empatizar con los personajes oprimidos. Se parte de sentir para luego razonar, criticar y proponer actuando... y después nuevamente sentir, etc. Es observarse a sí mismo en acción, y llegar con ello a despojarse de ideologías que creemos propias. La identidad es la que está actuando: el ser humano. Los argumentos sobre lo que debe hacerse ante un dilema moral se construyen a partir o junto con los sentimientos. El teatro del oprimido sirve como "termómetro" para saber de qué carecemos: cuál es la distancia que tenemos entre lo cognitivo y lo comportamental.

En el TO se va construyendo la identidad éticopolítica a partir del reconocimiento y la transformación de los sentimientos (si es necesario), que nos libera al momento de tomar decisiones plenas para la acción ético-política y no quedarnos en la mera buena intención. Cuando actuamos de manera improvisada sale nuestro ser más profundo: sin máscaras (paradójicamente) pero rico en personajes. Tan rico que al mostrarnos todas las caras que tenemos nos damos cuenta de la Unidad. Por ello podemos sentir compasión (ya que somos capaces de comprender al otro porque podemos ser él), y movernos para transformarnos en favor del anhelo común, según la filosofía oriental: la felicidad.

\section{A. Ejercer la ciudadanía para formarse como ciudadano}

Las competencias ciudadanas en Colombia recogen en buena medida el enfoque de la ciudadanía republicana (con sus virtudes y defectos: participación en la toma de decisiones pero respeto a las normas por deber); de la ciudadanía liberal (por la defensa de los derechos fundamentales y la tolerancia, pero sin formar para tener una mente abierta) y también del discurso crítico (valora el cuidado, pero no alcanza a cuestionar las relaciones de poder institucionalizadas o culturales o las ideologías presentes detrás de las leyes o costumbres sociales). Por otro lado, la política de formación ciudadana 
está centrada en la racionalidad mucho más que en las emociones (aunque sí se tienen en cuenta, considera que se deben controlar recurriendo a la razón). Es difícil predecir si alguien que responde adecuadamente las pruebas va a actuar de forma coherente con esas respuestas. Por lo mismo, la formación para obtener altos resultados en dichas pruebas no parece promover la acción ético-política.

Lo anterior aplica tanto para la educación básica y media como para la superior. Por ello es recomendable formar en pensamiento crítico y en disposición a la acción trabajando con, desde y para las emociones con un enfoque artístico (sensible y creativo) en la enseñanza de todas las asignaturas.

Se hace necesario permitir a los estudiantes actuar efectivamente en la construcción de su universidad. Por ejemplo, debería ser parte del proceso formativo la creación de espacios en los que los jóvenes manifiesten sus inconformismos y puedan proponer soluciones a los problemas que los afectan, e incluso actuar para resolverlos. Para ilustrar con un caso: poca utilidad tiene hablarles de la existencia de mecanismos legales de participación ciudadana, y luego evaluar en un examen su comprensión de los mismos, con la esperanza de que en un futuro los usen efectivamente (es decir, que den el salto de una educación heterónoma a la autonomía). En su lugar, convendría facilitarles el uso de estas figuras jurídicas (aún más, como pueblo soberano pueden inventar las formas que quieran) para transformar la misma universidad (sus normas o su cultura). Es difícil aprender a ser democrático sin serlo.
La condición de ciudadanía está estrechamente relacionada con la acción política de carácter público y colectivo (Ariza, 2007). Por esto la formación ciudadana debe incluir el ejercicio directo de la participación.

En este sentido, me parece interesante la propuesta de Augusto Boal (2001) desde el teatro del oprimido, pues sus técnicas (como el teatrolegislativo ${ }^{2}$ ) permiten que la misma comunidad diagnostique sus problemas y transforme su realidad. En palabras del autor (2009):

Vemos el mundo injusto y cruel. Tenemos la obligación de inventar otro mundo porque sabemos que otro mundo es posible. Pero nos incumbe a nosotros el construirlo con nuestras manos entrando en escena, en el escenario y en la vida.

... [H]agan sus obras ustedes mismos y vean lo que jamás pudieron ver: aquello que salta a nuestros ojos...

Actores somos todos nosotros, el ciudadano no es aquel que vive en sociedad: jes aquel que la transforma!

En especial, el teatro-legislativo permite formar ciudadanos experimentando en todo el ser la ciudadanía responsable liberal (protección de derechos individuales), republicana (pertenencia a una comunidad y tanto uso como creación de mecanismos de participación) y crítica (para lograr justicia social).

2 Inicia con un teatro foro y luego la comunidad -acompañada de un grupo de expertos en las disciplinas relevantes- elabora propuestas para un proyecto de ley que luego es llevado efectivamente al órgano legislador competente. 


\section{B. Corolario}

Antes de comenzar a aplicar las técnicas del teatro del oprimido de Augusto Boal este primer semestre de 2013 , les pedí a mis noventa estudiantes de Constitución y Democracia (C\&D) - de todas las carreras menos Derecho- que me escribieran en una hoja qué les molestaba de nuestra universidad. Para resumir, respondieron que: esta institución les roba el alma; los identifican por un número (el código), pierden su identidad; no son escuchados en los procesos disciplinarios, pues todo es por correo electrónico; las sanciones por fraude son desproporcionadas; no hay comunicación entre profesores y estudiantes; la cantidad de estudiantes por curso es muy grande; les dejan mucho trabajo; se promueve el individualismo y no el trabajo de grupo ni otras formas de integración; les exigen mucha memorización.

En febrero de este mismo año, la Decanatura de Estudiantes me pidió que apoyara la campaña Anti-fraude. Supieron del teatro-invisible y del teatro-foro que hice el semestre pasado en C\&D sobre acoso sexual, y les pareció una buena idea. Prometí tomar este tema para dichas técnicas, pero les dije que iba a agregar una: el teatro-legislativo. Les expliqué que necesitaría el compromiso del CAE (Comité de Asuntos Estudiantiles) para revisar la propuesta de modificación al Régimen Disciplinario de Uniandes ${ }^{3}$

3 De hecho, en una investigación se concluyó lo siguiente: "Proponemos como reflexión final nuestra preocupación más importante: las fuertes indicaciones de problemas de tipo curricular y pedagógico que se vislumbran a través de las razones que usan los estudiantes para justificar la comisión de fraude. Algunas características poco deseables de las evaluaciones y la carga académica son las razones que que les enviarían mis estudiantes. Consultaron y aceptaron...

\section{Bibliografía}

Ariza, A. (2007). Democracias, ciudadanías y formación ciudadana. Revista de Estudios Sociales $n^{\circ}$. 27. Agosto.

Boal, A. (2001). Juegos para actores y no actores. Barcelona: Alba Editorial.

Boal, A. (2009). Teatro del Oprimido: teoría y práctica. Barcelona: Alba Editorial.

Boal, A. (2009). Mensaje día mundial del teatro. Revista Artez. Recuperado el 2 de abril de 2013 desde: http://www.artezblai.com/artezblai/mensaje-del-dia-mundial-del-teatro2009-por-augusto-boal.html.

Chaux, E. (2004). Competencias ciudadanas: de los estándares al aula. Recuperado el 22 de febrero de 2013 desde: http://www.colombiaaprende.edu.co/html/mediateca/1607/ articles-75077_archivo.pdf.

Cullén, C. (2004). Perfiles ético-políticos de la educación. Barcelona: Paidós.

recibieron en promedio mayor calificación y que además resultaron buenas predictoras de la frecuencia aproximada de fraudes. Aquí hay un espacio importante que exige mayor investigación, discusión y trabajo con estudiantes, profesores y directivas para tomar decisiones, y probablemente realizar cambios, tanto a nivel de cursos individuales como a nivel institucional. Si tenemos en cuenta, por ejemplo, que las formas y contenidos de las evaluaciones de aprendizaje que se realizan en los cursos son, o deben ser, resultado lógico de los propósitos y los procesos de aprendizaje planeados y ejecutados en ellos, se hace indispensable estudiar no solo formas de evaluación sino metodologías de enseñanza y logros de aprendizaje con los cuales se asocian las formas de evaluación que actualmente se usan en diferentes tipos de cursos". (Mejía y Ordoñez, 2004). 
Dewey, J. (2007). Cómo pensamos. La relación entre pensamiento reflexivo y proceso educativo. Barcelona: Paidós.

Harnish, J. (2006). Contemporary Discourses of Cityzenship. Review of Educational Research, 76 (4), 653-690.

Kant, I. (2005). Respuesta a la pregunta ¿qué es la ilustración? En Filosofía de la historia. México: FCE.

Marx. K. (2007). El capital: crítica de la economía política. México: Siglo XXI Editores.

Mejía, J. Ordoñez, C. (2004). El fraude académico en la Universidad de los Andes. ¿Qué, qué tanto y por qué? Revista de Estudios Sociales, $n^{\circ}$. 18, agosto. Recuperado desde: http://res.uniandes.edu.co/view.php/352/ view.php

Ministerio de Educación Nacional. (2010). Competencias ciudadanas. Recuperado el 22 de febrero de 2013 desde: http://www.mineducacion.gov.co/1621/w3-article-235147.html

Norris, S. (1989). Evaluating critical thinking. Pacific Grove, CA: Midwest Publications.

Nussbaum, M. (2005). El cultivo de la humanidad: una defensa clásica de la reforma en la educación liberal. Barcelona: Paidós.

Ricard, M. (2009). Dalai Lama, imágenes de una vida. Barcelona: Random House.

Rorty, R. (1996). Contingencia, ironía y solidaridad. Barcelona: Paidós.

Schiller, F. (1990). Cartas sobre la educación estética del hombre. Anthropos.

Ueda, S. (2004). Zen y filosofía. Barcelona: Herder.

Watts, A. (1991). El camino del Tao. Barcelona: Editorial Kairós. 